\title{
Alianza del Pacífico: una visión desde Chile
}

\begin{abstract}
Discurso pronunciado por el Director Ejecutivo de la Fundación Chilena del Pacífico, Manfred Wilhelmy, en la 42a Sesión Ordinaria del Parlamento Andino.
\end{abstract}

Santiago, 17 de junio 2013

Agradezco muy especialmente esta oportunidad para dirigir unas palabras a los Honorables miembros del Parlamento Andino, que mi país se honra en recibir para esta sesión en Santiago.

Para la institución que represento, Fundación Chilena del Pacífico, dedicada a la promoción de las relaciones del país con la región Asia-Pacífico, la Alianza del Pacífico es un proceso en marcha y al mismo tiempo un proyecto de enorme importancia, tanta que hemos acordado en nuestro Consejo Directivo, en el marco de un plan estratégico recientemente aprobado, darle prioridad en nuestro programa anual de trabajo. En efecto, la dimensión latinoamericana de las vinculaciones con Asia-Pacífico ha sido una constante en el trabajo de la Fundación.

La Alianza del Pacífico es uno de los acuerdos de integración y cooperación de mayor trascendencia a que se ha incorporado nuestro país.

La Alianza tiene el potencial de transformar cualitativamente el espacio regional en que nos desenvolvemos en el comercio, la inversión extranjera directa, y las vinculaciones de cooperación, con una marcada orientación hacia el desarrollo de más y mejores relaciones externas del área de la Alianza, especialmente, pero no exclusivamente, en dirección al Asia-Pacífico. 
Es preciso sintetizar brevemente lo que ha sido nuestra política comercial, así como sus proyecciones.

Chile ha avanzado mucho en su proceso de integración económica y especialmente comercial con el mundo.

En una fase inicial, a través de sucesivos pasos unilaterales, el nivel de protección comercial disminuyó significativamente, hasta llegar al actual arancel nominal de $6 \%$ ad valorem, que se aplica en los contados casos en que no existe una preferencia arancelaria.

En el plano multilateral, Chile ha apoyado de manera consistente las rondas de negociación de la OMC y los acuerdos correspondientes, el último de los cuales fue el Acuerdo de Marrakech, resultante de la llamada Ronda Uruguay.

Posteriormente hemos apoyado el avance de la Ronda de Doha (Agenda de Desarrollo de Doha, DDA). Pero este proceso se encuentra estancado por razones conocidas, no imputables a los países de la Alianza, sin que se vislumbre hoy su pronta terminación exitosa.

Ese estancamiento es una importante motivación de nuestra voluntad de adelantar camino de apertura por otras vías, opción en la que hemos avanzado más que la gran mayoría de los partícipes en el comercio internacional.

En el nivel bilateral, tenemos ya acuerdos de libre comercio, de carácter preferencial, con la gran mayoría de los países de las Américas y de Europa, y estamos avanzando recientemente en la negociación y conclusión de importantes acuerdos adicionales en Asia, especialmente en la subregión del Sudeste.

En síntesis, los 22 acuerdos comerciales con 59 países, cifras del año 2012, cubren nuestros principales mercados, contribuyen a facilitar el desarrollo y penetración de los mercados de exportación, y han llevado nuestro arancel medio ponderado de importación a una cifra del orden del $\mathbf{1 \%}$.

De esta manera, aunque todavía quedan algunos países importantes con los que podríamos negociar este tipo de acuerdos, las estrategias bilaterales y subregionales o regionales necesitan ser complementadas mediante nuevas iniciativas, que no dejan sin efecto los acuerdos de este tipo, pero los sitúan en nuevos contextos y les agregan un nuevo potencial. Es el caso del Trans Pacific Partnership o TPP, y de la Alianza del Pacífico, cuyo objetivo es lograr una integración más profunda 
con países con los que ya tenemos acuerdos de libre comercio. Obviamente, nada de lo anterior anula nuestra vocación multilateral, pero debemos reconocer que la conclusión de la DDA excede el ámbito de influencia de nuestra política exterior económica.

La Alianza del Pacífico ha tenido un predecesor, la iniciativa del Arco del Pacífico Latinoamericano, una idea en sí loable, pero que al incluir a 11 países muy disímiles en tamaño, niveles de desarrollo y regímenes de comercio exterior, así como en otros aspectos de sus políticas públicas, no logró aunar efectivamente las voluntades de sus gobiernos y los respectivos sectores privados.

En cambio, la Alianza del Pacífico con sus cuatro países fundadores, un grupo más reducido pero con un alto grado de afinidad política y económica, ha permitido avanzar de manera mucho más ágil y operativa hacia la elaboración de acuerdos efectivos. Ello revela un sello realista del acuerdo.

La Alianza del Pacífico también es realista en un segundo aspecto: me refiero a la voluntad clara de trabajar con los protagonistas de las relaciones de comercio e inversión, los respectivos sectores privados donde están las empresas interesadas en la proyección regional de los negocios.

El Consejo de Empresarios de la Alianza del Pacífico está llamado a ser muy importante como vía de comunicación y de avance de iniciativas entre los gobiernos y las empresas, y noto entre los empresarios una real motivación de hacer del Consejo una instancia dinámica y efectiva. Creo que en la cumbre de Cali los empresarios han hecho planteamientos muy importantes. Esperamos que encuentren el eco que deben tener en los poderes públicos de los socios de la Alianza.

Entre otros aspectos, la voluntad de agilizar efectivamente la movilidad de personas de negocios y los movimientos migratorios laborales entre los países de la Alianza es una manifestación clara de lo que se quiere decir con "integración profunda". Obviamente, ello requiere un conjunto de medidas de ejecución cuidadosamente estudiadas, teniendo en cuenta consideraciones de seguridad, entre otras.

Pienso que el área de la normativa financiera y tributaria es de la mayor importancia para la viabilidad de los negocios en el área de la Alianza del Pacífico. En este ámbito se requie- 
re recopilar y evaluar antecedentes y formular propuestas específicas de acción legislativa y ejecutiva, para lo cual se ha propuesto la creación de una mesa de trabajo "ad hoc".

En el mismo sentido de integración profunda apuntan las iniciativas sobre intercambios académicos y estudiantiles, en su ámbito propio. Así se involucra efectivamente la sociedad civil, especialmente las generaciones jóvenes.

Al basarse en acuerdos comerciales preexistentes, la Alianza del Pacífico permite abreviar lo que de otro modo serían extensos y complejos procesos de negociación, complementando, armonizando y "agregando valor" a los tratados vigentes, que se mantienen, estableciendo vías y pasos adicionales para la creación de un espacio económico regional de considerables dimensiones. Sin duda, esta es una gran ventaja.

Otra característica que en mi opinión justifica esta apreciación es que la Alianza del Pacífico prescinde de instancias burocráticas internacionales para la administración del acuerdo, que suelen ser costosas para los países y no necesariamente agilizan la puesta en práctica de los acuerdos.

El mecanismo de una secretaría "pro tempore" de carácter rotativo me parece adecuado, y si con el progreso del acuerdo pudiera requerirse alguna instancia adicional de carácter técnico, ello podría plantearse en su momento, aportándose las justificaciones correspondientes.

La Alianza del Pacífico tiene el potencial de abrir una nueva etapa en las vinculaciones de los países participantes con la región Asia-Pacífico, la más dinámica en el contexto económico global. Como es sabido, una motivación importante en el establecimiento de la Alianza ha sido la voluntad compartida de potenciar este ámbito de nuestras relaciones externas.

Los grandes actores políticos y económicos de esa parte del mundo tradicionalmente han prestado poca atención a América Latina, entre otros factores porque las asimetrías de tamaño son muy marcadas, y las trayectorias de desarrollo han sido históricamente más bien divergentes.

Pero en la medida que los partícipes de la Alianza del Pacífico exhiben buenas y sostenidas tasas de crecimiento, estabilidad macroeconómica, sólidas cuentas externas, así como marcos institucionales consolidados, que distinguen a estos países en América Latina, tienen mejores capacidades 
para enfrentar coyunturas de crisis económica como las de los últimos años, y se vuelven socios atractivos para importantes economías asiáticas. Los antecedentes y datos económicos que conocen los Honorables parlamentarios así lo avalan, y pude comprobarlo personalmente en una reciente conferencia, Canadá - Asia 2013 (Vancouver, junio 2013), donde el interés por la Alianza fue muy alto.

No está demás recordar, por otra parte, que tres de los cuatro fundadores de la Alianza del Pacífico son miembros de APEC y además participan en las negociaciones del TPP, lo que refuerza este potencial de vinculación.

El hecho que importantes países de Asia-Pacífico, como Japón y Australia, sean observadores de la Alianza del Pacífico es en sí significativo. Existe también un buen potencial de desarrollo de vinculaciones entre la Alianza y la subregión de diez países del Sudeste Asiático agrupada en ASEAN. Deberíamos enfatizar como Alianza las relaciones con el área ASEAN, como un complemento de nuestras respectivas prioridades nacionales.

Una buena noticia adicional ha sido el interés europeo en la Alianza del Pacífico, que se ha expresado a través de España como observador, y en las declaraciones favorables a la Alianza de la Canciller Federal alemana, Angela Merkel, formuladas en Santiago cuando la gobernante alemana asistió a la cita CELAC / UE. En el ámbito americano, se agrega el interés de un país importante, socio consolidado en el comercio, la inversión y la cooperación, como es Canadá.

En síntesis, los antecedentes indican que la A. del P. es una manifestación renovada del regionalismo abierto por el que Chile ha venido abogando por mucho tiempo. La Alianza está llamada a ser un instrumento central de re-posicionamiento externo y de desarrollo regional, y a aportar una visión estratégica renovada de los poderes públicos y la sociedad civil. Ello requerirá realizar acciones concertadas y sostenidas, un sólido trabajo con visión de futuro en conjunto con todos los miembros de la Alianza

Hacia el final de estas consideraciones, permítanme agregar algunos aspectos específicos.

Frente al Parlamento Andino me permito destacar especialmente la cláusula democrática. 
El artículo 2, al establecer como requisito esencial para la participación de las partes la vigencia del Estado de derecho, la democracia, los respectivos órdenes constitucionales, la separación de los poderes del Estado, y la protección, promoción y respeto de los derechos humanos y libertades fundamentales, es un elemento político de gran importancia dentro del Acuerdo, que no podría considerar el ingreso de países que no fueran Estados de derecho y democracias representativas, ni la continuación de la participación de aquellos miembros que perdieran dichas condiciones.

De esta manera, las democracias pactantes se apoyan mutuamente entre sí, favoreciendo la estabilidad regional, reafirman valores fundamentales y establecen una vinculación explícita entre sus regímenes políticos y las políticas públicas en el ámbito de la integración económica y social.

Otra norma de importancia política es el art. 6, que al establecer la regla del consenso para la adopción de acuerdos de los órganos de la Alianza, parece una norma sensata, que incentiva la cabal negociación previa de los asuntos que requieran decisiones comunes.

Agreguemos que el art. 12 prevé la eventual adhesión de miembros adicionales, a los cuales se les exige tener vigentes acuerdos de libre comercio con cada uno de los estados parte de la Alianza. Ello deja abierta la puerta a un crecimiento orgánico, que al darse sobre la base de acuerdos previos evitará una proliferación de solicitudes de países que pudieran no ser socios viables del área de integración.

En cuanto a las políticas de la A. del P., en el plano de la potenciación de las exportaciones de la región, la adopción de reglas de origen acumulativas de carácter regional parece particularmente acertada para la conformación de un espacio económico mayor, interesante para nuestras contrapartes en el resto del mundo y para inversionistas extranjeros con potencial exportador desde los países de la Alianza.

La cooperación entre los respectivos servicios o agencias nacionales de promoción de exportaciones es otro rasgo distintivo de lo que se llama "integración profunda". Abarcando desde simples "comunidades de techo" que permiten disminuir costos y contar con mejores instalaciones en el exterior, hasta ciertos programas de oferta integrada de bienes y servicios, 
esta forma de cooperación expresa de manera clara y potente el ánimo de cooperación, prometiendo frutos que pueden beneficiar a todos.

Ello, naturalmente, con las limitaciones y resguardos del caso en áreas o productos que pudieran competir al interior de la Alianza - pero aún en esta hipótesis es posible pensar en acuerdos convenientes para todos o algunos de los socios.

Todo indica que la Alianza del Pacífico es un acuerdo internacional de enorme potencial. No es un acuerdo dirigido "contra" otros en la región, por lo que no debería despertar suspicacias de orden político. Obviamente, ha nacido de concepciones compartidas en materia de comercio y desarrollo, lo que es natural de una alianza y diferencia a quienes están en ella de países que no participan. Pero ya hemos visto que si otros cumplen ciertos requisitos, principalmente la vigencia de tratados de libre comercio con cada uno de los miembros, podrían unirse a este esfuerzo común.

Es un acuerdo a favor de la cooperación para el desarrollo a través de la integración comercial, y más allá de ella, comprometiendo tanto a los gobiernos como al sector privado de cada uno de los países participantes.

Potenciar la Alianza nos parece una tarea motivante, que llevada a cabo de manera competente y dedicada podrá redundar en beneficio no sólo de sus miembros, sino de los países andinos y toda América Latina.

Muchas gracias 